\section{Apical Barrier Formation After Incomplete Orthograde MTA Apical Plug Placement in Teeth with Open Apex - Report of Two Cases}

Spyros G. Floratos ${ }^{1}$, loannis N. Tsatsoulis², Evangelos G. Kontakiotis ${ }^{2}$
'Endodontics Private

Practice, Athens, Greece

${ }^{2}$ Department of Endodontics, Dental School, University of

Athens, Athens, Greece

Correspondence: Spyros G. Floratos, DMD, 13 Koniari Str, Athens, 114 71, Greece. Tel.: +30-210-6427232. e-mail: sflo_@hotmail.com
Two cases are reported in which incomplete placement of $4 \mathrm{~mm}$ mineral trioxide aggregate (MTA) plug was performed unintentionally at the apical third of permanent immature teeth with open apex and apical periodontitis. As confirmed radiographically, there were gaps between MTA and dentinal walls along the MTA-dentin interface. After setting of MTA was confirmed, endodontic treatment was completed and access was sealed with composite resin. At 6 to 16 months follow-up examinations, formation of dentin in contact with the MTA surface, as well as apical closure and periapical healing were identified radiographically for both cases. The results of these cases showed that apical barrier formation and complete periapical healing is possible despite the incomplete apical placement of the MTA plug. This might be due to the biological properties of the MTA. Even so, an incomplete three-dimensional placement of the filling material is not advocated.
Key Words: apexification, open apex, permanent teeth, MTA plug, barrier formation.

\section{Introduction}

Mineral trioxide aggregate (MTA) is reported to have a variety of potential uses, including as a root canal filling material (1). Studies have demonstrated regeneration of periradicular tissues, such as periodontal ligament, bone, and cementum, by use of MTA in endodontic procedures (2-6). Its superior biocompatibility with periodontal tissues has also been reported $(7,8)$, as well as an excellent sealing ability in the presence of moisture $(9,10)$, and adequate mechanical properties as an apical sealing material (11). Considering these encouraging results, many clinicians have used MTA as a root end filling material and as a material suitable for repairing perforations and performing apexification (3-6).

The application of MTA instead of calcium hydroxide for apexification of immature roots is based on its ability to facilitate normal periradicular architecture by inducing hard tissue barriers (5). MTA has also presented promising outcomes when used for the repair of lateral and furcation perforations (12).

On the basis of these findings, MTA could be an appropriate material for apical sealing of immature root canals with open apices, particularly in cases where obtaining an adequate obturation and seal with placement of a complete MTA plug is technically difficult and challenging.

The following case reports demonstrate the formation of an apical barrier on permanent immature teeth with open apices, even after incomplete three-dimensional placement of MTA apical plugs.

\section{Case Report}

\section{Case 1}

A 10-year-old female patient presented at the private office with an intraoral swelling and pain on both maxillary central incisors. The patient's parents reported that she had suffered trauma to permanent maxillary right and left central incisors one year before at which time the crowns were fractured and restored with composite resin by their dentist at the day of the accident. No tooth dislocation or mobility was noted by her dentist at that time.

Clinical examination revealed a labial sinus tract at the apical area of the right central, which was accompanied by intraoral swelling at the same area. Both central incisors were symptomatic to percussion and palpation. Diagnostic testing was negative on cold and electric pulp testing for both teeth. Radiographic examination demonstrated that both central incisors had an immature apex and periradicular radiolucency (Fig. 1A). The crowns of both teeth had composite resin restorations. Based on clinical and radiographic findings, the diagnosis of pulp necrosis and symptomatic apical periodontitis was made for both teeth.

Endodontic therapy was carried out under local anesthesia and with rubber dam isolation of both incisors. When the access cavity was made, pulp necrosis was verified on both teeth. Working length was confirmed radiographically with a size 80 Hedstrom file (Dentsply Maillefer, Ballaigues, Switzerland). Biomechanical preparation was done by circumferential filing with a size 80 Hedstrom file and copious irrigation with 2.5\% 
$\mathrm{NaOCl}$. After biomechanical preparation, the root canal was dried and filled with a paste prepared with distilled water and calcium hydroxide powder (Calcium Hydroxide USP Pure; Merck KGaA, Darmstadt, Germany) with the aid of engine-driven lentulo spirals. The access cavity was sealed with zinc oxide and eugenol cement. After 1 week, the calcium hydroxide was removed by repeated rinsing with $2.5 \% \mathrm{NaOCl}$. The canal was dried with sterile paper points. Starting from the left central incisor, an MTA mixture (ProRoot MTA; Dentsply Tulsa Dental Specialties, Tulsa, OK, USA) was made and placed with an MTA carrier (Dovgan MTA Carrier $0.9 \mathrm{~mm}$ bendable, Quality Aspirators, TX, USA), under the operating microscope (Carl Zeiss OPMI PICO, Jena, Germany) in the apical portion of the canal (4 $\mathrm{mm}$ ) to create an apical plug. After the positioning of the MTA apical plug, the mixture was adapted to the canal walls using a No70 hand plugger, proportional to the apical gauge. The same procedure was repeated for the right central incisor.

To verify the correct position of the MTA mixture, an $x$-ray control was done. In the case of the left central incisor, the x-ray showed that the placement of MTA was incomplete at the last $2 \mathrm{~mm}$, as there was a gap in between $\therefore$ the MTA plug and the root canals walls both on the mesial and distal aspect of the MTA portion (Fig. 1B). A cotton pellet soaked with sterile water was then placed in the pulp chamber and the access cavity was sealed with zinc oxide and eugenol cement (ZOE). During the session, as well as at all subsequent treatment sessions, the patient was nervous and hard to cooperate. After 3 days, the ZOE and cotton pellet were removed and the set of the MTA was tested by gently touching it with a hand file. The rest of the canal was obturated with thermoplastic gutta-percha applied (Obtura II; Obtura Spartan, Fenton, MO, USA) in association with a canal sealer (AH-Plus; Dentsply Tulsa Dental Specialties) (Fig. 1C). The coronal access was later sealed with composite resin. At the 6 month follow-up examination, the patient was asymptomatic and healing of the periapical lesion was noted radiographically (Fig. 1D).

The radiographic follow up at 16 months revealed apical closure of the open apex of the left central incisor (Fig. 1E).

\section{Case 2}

A 12-year-old male patient was referred to the Department of Endodontics of the Dental Hospital of University of Athens by the Department of Pediatric Dentistry for evaluation and treatment of the maxillary right central incisor. The patient's dental history revealed that he had suffered a trauma to the maxillary right and left central incisors 4 years before, with intrusion of both teeth. An endodontic treatment was started on the maxillary right central incisor 18 months later, after the tooth had partially erupted. According to his chart, the patient had undergone several treatment sessions that aimed to the formation of a dentin bridge and had also started orthodontic treatment. At his referral to the Department of Endodontic, the patient was clinically and radiographically examined. The right central incisor was asymptomatic to percussion and palpation, and diagnostic testing was negative to cold and electric pulp testing. Radiographic examination demonstrated that the right central incisor had an incompletely developed apex and periradicular radiolucency (Fig. 2A). The crown had a glass ionomer cement restoration. Based on clinical and radiographic findings, the diagnosis of pulp necrosis and asymptomatic apical periodontitis was made for the right central incisor.

Endodontic therapy was carried out under local anesthesia and with rubber dam isolation. When the access cavity was prepared, a dentin bridge formation was identified at the coronal third of the central incisor using the microscope (Global; Global Surgical ${ }^{\mathrm{TM}}$ Corporation, St. Louis, MO, USA) and confirmed by finding resistance on
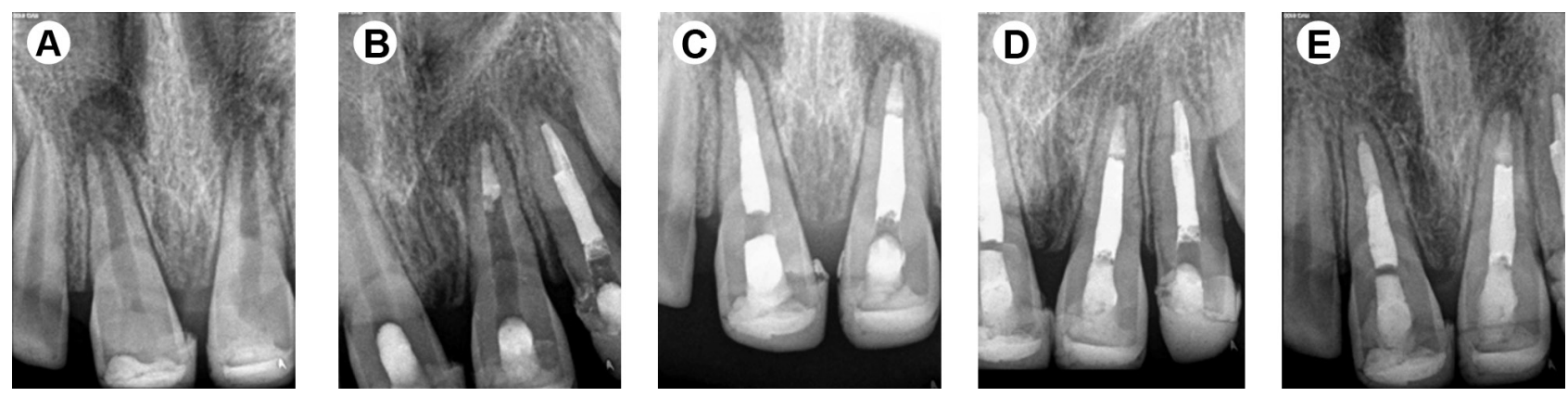

Figure 1. Case 1 - treatment sequence and recall evaluations. A: Preoperative radiograph demonstrating apparent radiolucency and open apex on both central incisors. B: Intraoperative radiograph showing incomplete MTA placement and presence of gaps in between MTA and the dentin surface on maxillary left central incisor. C: Postoperative radiograph. D: Radiograph taken at 6 months. E: Radiograph taken at 16 months. 
the barrier with a size 80 gutta-percha cone. The dentin bridge was penetrated using an ultrasonic tip to facilitate instrumentation on the rest of the canal wall surface and a size $15 \mathrm{~K}$-file was gently pushed through the penetration (Fig. 2B). Working length was confirmed radiographically with a size 40 Hedstrom file (Fig. 2C). Biomechanical preparation was done by circumferential filing with a size 80 Hedstrom file and copious irrigation with $2.5 \% \mathrm{NaOCl}$. Next, the root canal was dried and filled with a calcium hydroxide/distilled water paste with the aid of enginedriven lentulo spirals. The access cavity was sealed with glass ionomer cement (GC Fuji I; GC Corporation, Tokyo, Japan). After 1 week, the calcium hydroxide dressing was removed by repeated rinsing with $2.5 \% \mathrm{NaOCl}$. The canal was dried with sterile paper points. An MTA mixture (ProRoot MTA, Dentsply) was made and placed with the MTA carrier (Dovgan MTA Carrier $0.9 \mathrm{~mm}$ bendable) in the apical portion of the canal to create an apical plug of $4 \mathrm{~mm}$ in thickness. The proper positioning and alignment of the MTA carrier to the premeasured length was disrupted by remnants of the dentin bridge at the coronal part. After the positioning of the MTA apical plug, the mixture was adapted to the canal walls using a No. 70 hand-plugger, proportional to the apical gauge. To verify the correct position of the MTA mixture, an $\mathrm{x}$-ray control was done. The $\mathrm{x}$-ray showed that the placement of MTA was incomplete, as there was a gap in between the MTA plug and the root canals walls both on the mesial and distal aspect of the MTA portion (Fig. 2D). A cotton pellet soaked with sterile water was then placed in the pulp chamber and the access cavity was sealed with ZOE. After 3 days, the ZOE filling and the cotton pellet were removed and the set of the MTA was tested by gently touching it with a hand file. The rest of the canal was obturated with thermoplastic gutta-percha applied in association with a canal sealer (AH-Plus). The coronal access was later sealed with composite resin. At the 1 year follow-up examination the patient was asymptomatic and healing of the periapical lesion was noted radiographically (Fig. 2E). In addition, complete formation of the dentinal walls in contact with the MTA surface as well as apical closure was observed (Fig. 2E).

\section{Discussion}

MTA has drawn much interest because of its numerous applications. MTA has shown a significantly greater frequency of dentin bridge formation, thicker and less porous dentin, and less pulp inflammation compared with calcium hydroxide (12-16). MTA has also been shown to induce the recruitment and proliferation of undifferentiated cells to form a dentin bridge while reducing inflammation compared with calcium hydroxide (14). Another research has shown that MTA when placed in direct contact with the human dental pulp cells (DPCs) differentiated them into odontoblast-like cells (17). In vitro experiments have shown that MTA up-regulated the expression of type I collagen and osteocalcin in osteoblasts after $24 \mathrm{~h}$ (18). Other research studies have shown that MTA stimulates the proliferation of cementoblasts, fibroblasts, and osteoblasts (19). MTA has also been shown to permit cementoblast attachment and growth as well as the production of mineralized matrix gene and protein expression (20).

The present case reports confirm that an apical barrier formation can occur even in the presence of gaps between the MTA plug and the root canal walls. This observation is probably related to the ability of MTA to enhance cell migration (21). Migration of human bone marrow stem cells in the presence of MTA was shown in a recent study, by use of transwell cell culture inserts in 6-well plates
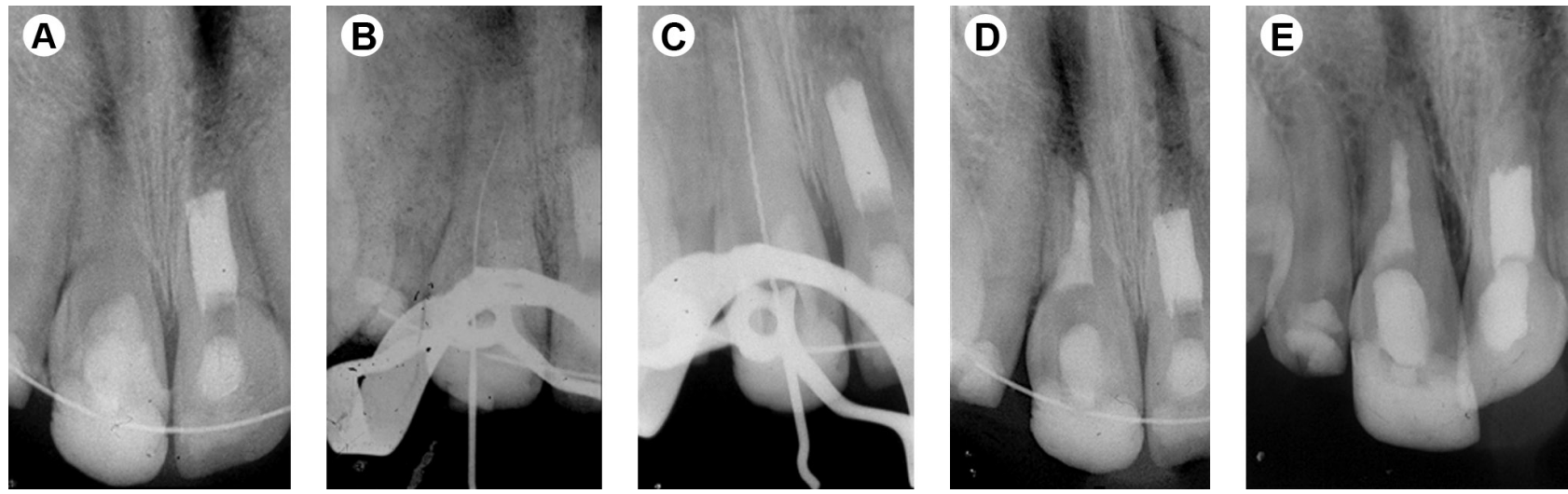

Figure 2. Case 2 - Treatment sequence and recall evaluations. A: preoperative radiograph demonstrating apparent radiolucency and open apex on tooth maxillary right central incisor. B: Dentin bridge penetrated with a size $15 \mathrm{~K}$-file. C: Working length was confirmed radiographically with a size 40 Hedstrom file. D: Postoperative radiograph showing incomplete MTA placement and presence of gaps in between MTA and the dentin surface. E: Radiograph taken at 12 months. 
(21). The interaction of cells with materials used for root perforation and resorption repair, apexogenesis, and apical surgery could play a critical role in the healing of injured tissues. Bone and periodontal healing/regeneration is a complex event that involves the coordination of a variety of different stages (22), in which the migration and invasion of multipotent mesenchymal stem cells are required (23). The ability of MTA to moderate the migration of cells should probably be considered to be an important stage in the induction of tissue repair.

When MTA plug was used for apical barrier formation, the time taken to form a biological apical barrier, as assessed radiographically, was significantly less $(3.0 \pm 2.9$ months) than the dentinal barrier formed by using calcium hydroxide (24). In the present study, the formation of an apical barrier with gaps on the interface between MTA and dentinal walls was significantly delayed compared with the aforementioned time periods. In Case 1, apical closure on the maxillary left central incisor was observed at 16 months, whereas for the maxillary right central incisor that went through the same procedure, a barrier formation was observed at the 7-month recall. The difference for the right central incisor was that the MTA plug was placed in complete contact with the dentinal walls. In Case 2, the time for apical closure on the maxillary right central incisor was 12 months.

The two case reports showed that MTA apical plug can be considered very effective in stimulating regeneration of apical tissue in immature permanent teeth with open apices, even if direct contact of the material with the root canal walls is not achieved at some parts of the MTA-dentin interface.

\section{References}

1. Bogen $\mathrm{G}$, Kuttler $\mathrm{S}$. Mineral trioxide aggregate obturation: a review and case series. J Endod 2009; 35:777-790.

2. Stefopoulos S, Tzanetakis GN, Kontakiotis EG. Non-surgical retreatment of a failed apicoectomy without retrofilling using white mineral trioxide aggregate as an apical barrier. Braz Dent J 2012; 23:167-171.

3. Torabinejad $\mathrm{M}$, Chivian N. Clinical applications of mineral trioxide aggregate. J Endod 1999;25:197-205.

4. Mente J, Hage N, Pfefferle T, Koch MJ, Dreyhaupt J, Staehle HJ, Friedman S. Mineral trioxide aggregate apical plugs in teeth with open apical foramina: a retrospective analysis of treatment outcome. J Endod 2009;35:1354-1358.

5. Moore A, Howley MF, O'Connell AC. Treatment of open apex teeth using two types of white mineral trioxide aggregate after initial dressing with calcium hydroxide in children. Dent Traumatol 2011;27:166-173.

6. Cehreli ZC, Sara S, Uysal S, Turgut MD. MTA apical plugs in the treatment of traumatized immature teeth with large periapical lesions. Dent Traumatol 2011; 27:59-62.
7. Katsamakis S, Slot DE, Van der Sluis LW, Van der Weijden F. Histological responses of the periodontium to MTA: a systematic review. J Clin Periodontol. 2013;40:334-44.

8. Torabinejad M, Hong CU, Lee SJ, Monsef M, Pitt Ford TR. Investigation of mineral trioxide aggregate for root end filling in dogs. J Endod 1995;21:603-608.

9. Torabinejad $M$, Watson TF, Pitt Ford TR. Sealing ability of a mineral trioxide aggregate when used as a root end filling material. J Endod 1993;19:591-595.

10. Torabinejad M, Higa RK, McKendry DJ, Pitt Ford TR. Dye leakage of four root end filling materials: effects of blood contamination. J Endod 1994;20:159-163.

11. Torabinejad M, Hong CU, McDonald F, Pitt Ford TR. Physical and chemical properties of a new root-end filling material. J Endod 1995;21:349-353.

12. Pitt Ford TR, Torabinejad M, McKendry JD, Hong CU, Kariyawasam SP. Use of mineral trioxide aggregate for repair of furcal perforations. Oral Surg Oral Med Oral Pathol Oral Radiol Endod 1995;79:756-762.

13. Chala $S$, Abouqal $R$, Rida $S$. Apexification of immature teeth with calcium hydroxide or mineral trioxide aggregate: systematic review and meta-analysis. Oral Surg Oral Med Oral Pathol Oral Radiol Endod 2011;112:e36-e42.

14. Holland R, Filho JA, de Souza V, Nery MJ, Bernabe PF, Junior ED. Mineral trioxide aggregate repair of lateral root perforations. J Endod $2001 ; 27: 281-284$.

15. Nair PN, Duncan HF, Pitt Ford TR, Luder HU. Histological, ultrastructural and quantitative investigations on the response of healthy human pulps to experimental capping with mineral trioxide aggregate: a randomized controlled trial. 2008. Int Endod J 2009;42:422-444.

16. Pitt Ford TR, Torabinejad M, Abedi HR, Bakland LK, Kariyawasam SP. Using mineral trioxide aggregate as a pulp-capping material. J Am Dent Assoc 1996;127:1491-1494.

17. Paranjpe $A, Z$ hang $H$, Johnson JD. Effects of mineral trioxide aggregate on human dental pulp cells after pulp-capping procedures. J Endod 2010;36:1042-1047.

18. Tani-Ishii N, Hamada N, Watanabe $K$, Tujimoto $Y$, Teranaka T, Umemoto T. Expression of bone extracellular matrix proteins on osteoblast cells in the presence of mineral trioxide. J Endod 2007;33:836-839.

19. Hakki SS, Bozkurt SB, Hakki EE, Belli S. Effects of mineral trioxide aggregate on cell survival, gene expression associated with mineralized tissues, and biomineralization of cementoblasts. J Endod 2009;35:513519.

20. Thomson TS, Berry JE, Somerman MJ, Kirkwood KL. Cementoblasts maintain expression of osteocalcin in the presence of mineral trioxide aggregate. J Endod 2003;29:407-412.

21. D'Antò V, Di Caprio MP, Ametrano G, Simeone M, Rengo S, Spagnuolo G. Effect of mineral trioxide aggregate on mesenchymal stem cells. J Endod 2010;36:1839-1843.

22. Polimeni G, Xiropaidis AV, Wikejso UM. Biology and principles of periodontal wound healing/regeneration. Periodontol 2000; 2006;41:30-47.

23. Schindeler $A$, McDonald MM, Bokko $P$, Little DG. Bone remodeling during fracture repair: the cellular picture. Semin Cell Dev Biol 2008;19:459-466.

24. Pradhan DP, Chawla HS, Gauba K, Goyal A. Comparative evaluation of endodontic management of teeth with unformed apices with mineral trioxide aggregate and calcium hydroxide. J Dent Child 2006;73:79-85.

Received January 8, 2013 Accepted April 2, 2013 